Prof. Wyville Thomson succeeded me on the Igth of July, and made a short but very successful cruise to the northern part of the Bay of Biscay, where he dredged at the extraordinary depth of 2,435 fathoms, or I4,6 Io feet. Some particulars of this dredging I have already given. Dr. Carpenter replaced Prof. Wyville Thomson on the I th of August, and explored the sea-bed lying between the north of Scotland and the Faröe Isles. The depths there dredged did not exceed 650 fathoms; but the results are most interesting and important in a biological as well as physical point of view. Prof. Wyville Thomson accompanied Dr. Carpenter in the last part of the expedition. It terminated on the 7 th of September.

(To be continued.)

$$
\text { J. GWYN JEFFREYS }
$$

\section{UTILISATION OF SEWAGE}

$W^{E}$ have been requested by the Secretary of the Committee * of the British Association on the Treatment and Utilisation of Sewage, to print the following letter, which has been sent to the Municipal Authorities throughout the country :-

$$
\text { 22, Whitehall Place, London, S.W. }
$$
November I 8 th, I869.

SIR,--I have the honour to inform you that, last year, at the meeting of the British Association at Norwich, a Committee was appointed to report on the Treatment and Utilisation of Sewage. In the first instance, a grant of $£$ ro was placed at the disposal of the Committee, with which to defray the cost of printing and postage incidental to the collection of preliminary statistical information. Through the kindness of Her Majesty's Government, the Committee was enabled to obtain Reports respecting the methods of dealing with town refuse practised in most civilised countries, and that information has now been collected in a more complete form than hitherto existed in any country.

This preliminary work being completed, the Committee was re-appointed at the meeting of the British Association this year at Exeter, and the inquiry was considered to present such important features of social and scientific interest, that the sum of 650 was voted towards enabling the Committee to enter more fully and practically upon the investigation of this subject. The British Association being a purely scientific body, has not at its disposal funds which would be adequate or applicable for the full prosecution of this very large and pressingly-important inquiry. The Committee nevertheless desires to take advantage of the opportunity created by the British Association, to investigate the entire subject in all its bearings-whether chemical, physiological, or engineering, sanitary, municipal, or agricultural-and in a manner worthy of the body they represent.

It is unnecessary to point out the enormous importance, especially at the present time, of a full and complete investigation of this question by the light of the knowledge and experience now gained in the several departments above alluded to ; but properly to carry out such an inquiry with a practical end, numerous observations, gaugings, and experiments, aided by simultaneous analyses, are essential; and these cannot be accomplished, especially the analyses, without the continued aid of efficient and therefore highly-paid assistants. Moreover, from time to time it may be necessary for the Committee to purchase extensive apparatus, and to subject various inventions and processes to a thorough and complete test; for it is the desire of the Com mittee, not only to ascertain, as far as possible, the causes of the sanitary inefficiency of existing works, but also to inquire into every suggestion which affords promise of practical utility, in order that this investigation may be searching, the report practical, and any recommendations that may be made authoritative.

It is the wish of the several members of the Committee to devote, to the utmost of their ability, their personal attention to the work thus sketched out; but the expenses absolutely necessary to enable them to conduct so extended an inquiry cannot but be

* The following are the names of the Committee:-Richard B. Grantham, Esq., M. Inst. C.E., F.G.S., Chairman; J. Bailey Denton, Esq., M. Inst. C.E., F.G.S.; J. Thornhill Harrison, Esq., M. Inst. C.E.; Benjamin H. Paul, Esq., Ph.D., F.C.S.; Profess Wanklyn, F.C.S.; William Hope Esq V.C.; Professor Williamson, Ph.D., F.R.S; Professor Marshall, F.R.S. F.R.C.S.; Professor Corfield, M.A., M.D.; M. C. Cooke, Esq.; and Sir John Lubbock, Bart., F.R.S., Treasurer. Subscriptions should be paid to the credit of Sir John Lubbock, on behalf of the Committee, at Messrs. Robarts, Lubbock, and Co.'s, I5, Lombard Street, London, E.C. very heavy, and, unless they are able to secure an adequate fund, they must abandon the attempt to investigate the subject in this broad and comprehensive manner. However, since there is no subject of greater practical and social importance to the public generally, and thus to the various municipal anthorities and other governing bodies throughout the conntry, it is believed that many will share the opinion expressed at the recent meeting of the British Association at Exeter, that the existence of this Commit tee affords a specially favourable opportunity for such a wide inquiry, and for that reason its members confidently appeal to those authorities who are officially interested in the subject to supply the funds necessary for the investigation.

I am therefore desired to request that you will kindly submit this letter to the body you represent, and I venture to hope you will give the Committee the benefit of your good offices in procuring a subscription proportionate to the population of your town or district.

It is suggested that the subscriptions of towns of different populations might be graduated somewhat in the following proportions:-

Where the population does not exceed 10,000 $.65 \quad 50$

Between IO,000 and 25,000... . . . IO IO O

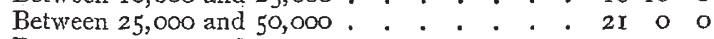

Between 50,000 and 75,000...... . 30 . 0

Between 75,000 and 100,000 ...... 50 00

Above 100,000 . . . . . . . . . . . 100 00

I beg to call your attention to the accompanying list of mem. bers of the Committee, and to inform yout that all public bodies subscribing not less than 5 . 5 s. od. will have the benefit of the information from time to time, as the results of the inquiry partake of a conclusive character, and will receive a copy of the report of the Committee when published.

I have the honour to be, \&c.,

GroRgE F. BARNES,

Honorary Secretary pro iem.

\section{TELEGRAPHIC COMMUNICATION WITH} FRANCE

AST Tuesday, November 3o, the S.S. William Cory left Greenhithe with a heavy submarine cable, to be laid between Salcombe in Great Britain and Cape Finisterre in France. This cable, I05 miles long, has just been made by the Telegraph Construction and Maintenance Company, at their works at North Woolwich, and its special object is to establish direct telegraphic communication between London and Brest, so as to expedite the transmission of messages between Great Britain and America by the French Atlantic Cable.

The new cable is very strong and heavy. The shore ends weigh 20 tons to the mile, and the deep-sea portion weighs very riearly Io tons to the mile. It contains one conductor only, consisting of a strand composed of seven copper wires, and weighing, when twisted together, 107 pounds to the mile. The insulating medium is gutta-percha, and weighs 166 pounds to the mile. The contractors undertook that the electrical resistance of the conducting strand should not exceed 12.25 ohms per mile, and that the insulation resistance should not be less than 200 megohms (million ohms), at the standard temperature of 24 degrees centigrade. So well have the contractors done their work, that the quality of the cable is better than agreed upon, the conductivity resistance being only in 8 ohms, and the insulation resistance nearly 400 instead of only 200 megohms per knot. The inductive capacity of this cable is as nearly as possible 333 Farad. per mile.

The William Cory, since 1858 , has laid many submarine cables; she carried and laid portions of the French Atlantic cables last summer, and is now employed solely in this new branch of industry. Captain Donaldson has been in charge of her throughout the whole of this period and he took her out again last Tuesday, on which day she left Greenhithe for Salcombe. For the above details relating to the conductivity, insulation, and capacity of the cable, we are indebted to Mr. C. F. Varley, C.E., engineer to the French Atlantic Telegraph Company, who accompanies the expedition. 'The apparatus used in testing the cable 
was that described by his brother before Section $A$ of the British Association at Exeter. By the time these lines are in print the cable may possibly have been laid, but much depends upon the weather. When the weather is fine, it usually takes half a day to lay each of the shore ends of a cable, and the deep-sea portion is ordinarily paid out at the rate of five knots per hour. The time occupied in paying out the deep-sea portion of the cable now under notice should be about twenty hours in all.

\section{DR. PENNY, F.R.S.E.}

$N$ our first number.we had to record the death of Thomas Graham, one of the greatest chemists of the century, and formerly an occupant of the.chair of chemistry in Anderson's Institution, Glasgow. We have now to announce the death of Frederick Penny, who, with the exception of the short interval between 1837 and 1839 , when Gregory was its occupant, has filled it with increasing reputation and success ever since Graham vacated it to go to London, thirty-two years ago. Born in London in I8I 7 , he was devoted to chemistry from his earliest years, and studied in the Apothecaries' Hall under Henry Hennell, F.R.S. It was while here that he was led to inquire into the combining weights of certain of the elements, by finding that the amount of potassic chloride obtained by acting upon pure potassic nitrate with excess of hydrochloric acid did not correspond with the quantity which theory showed should be obtained. Having made sure that the difference was not due to errors in his experiments, he ascribed it to inaccurate equivalents assigned to the elements. As the result of his investigations, he showed that the equivalents current at the time for chlorine, nitrogen, potassium, sodium, and silver were not in strict accordance with experiment, and that the "hypothesis of all equivalents being simple multiples of hydrogen is no longer tenable." [Phil. Trans. I 839. Part i. p. 32.] There can be no question as to the clearness of this paper and the value of the results obtained, and our interest in them is in no way diminished when we find that the equivalents determined by Penny agree in a very remarkable manner with the mean numbers published by Stas, and that this agreement has been pointed out by that chemist. [Fresenius, Zeits. für Annal. Chem. I868, pp. 164; I68. Compare Penny's Table, Phil. Trans. I839, i. p. 32, with Stas's Fres. Zeits. 1868, p. I70.]

The paper was published in January 1839 , and the same year he was appointed to the vacant lecturership in Anderson's Institution. Dr. Penny himself has had but recently to give an account of his struggles and successes in Glasgow, since settling in it thirty years ago. Recommended by Graham, he went down to a sphere of life and action, more strange at that time to a native of London than it has since become; but he devoted himself strenuously to his work, and at the time of his death had won in Glasgow and the West of Scotland a wide reputation as one of the clearest and most emphatic lecturers, and one of the most painstaking teachers.

\section{LETTERS TO THE EDITOR}

[The Editor does not hold himself responsible for opinions expressed by his Correspondents.]

\section{Lectures to Working Men}

I HEARTILY concur in Mr. Stuart's opinion, that the working men of England-speaking at least for the North-are fully aware of the value of Scientific Instruction in its strict sense. 'The subject has a special interest for me; as in the winter of 1866-7, I started in this city a series of Science Lectures for the People, which, with the kind help of Prof. Jevons, Dr. Alcock, and Dr. Morgan, were undertaken for the purpose of ascertaining whether the working men of Manchester really appreciate the value of science instruction when given in a plain, but scientific form, illustrated with diagrams and experiments made on a scale such as could be seen by a large audience. The experiment proved highly successful. Upwards of 4,000 people attended the thirteen Lectures which we gave, and the class of persons present was exactly that for whom the lectures were designed; whilst the marked attention and interest invariably exhibited by the audiences showed how keenly they appreciated the information they received, and the insight into true scientific methods which they obtained.

The lecturer's words were taken down by Mr. Pitman, and the lectures were each week printed and published by Mr. John Heywood; of Manchester, and largely sold at one penmy each at the door of the lecture-room and elsewhere. I printed syllabuses of the chief points of my four lectures, and one was given to each person entering the room. When I say that the subject of my first lecture was the explanation of the principles of the Indestructibility of Matter and of Energy, with a description of Jonle's Determination of the Mechanical Equivalent of Heat, I think you will see that mere amusement was not the aim; the sane remark applies to all the other lectures, and yet I never met with a more attentive and appreciative audience than these Manchester working men.

Professor Jevons gave us a most excellent lecture on "Coal, its Value and Importance in the Arts and Sciences;" Dr. Alcock gave four capital lectures on Elementary Zoology, and Dr. Morgan a course of four on Elementary Physiology, a subject in which the greatest interest was evinced.

We charged one penny per head for admission, and the penny fees did not nearly cover the necessary outlay, which was defrayed by some friends. Not only was the expense a difficulty, but the work of carrying on such a system was more than could be regularly and gratuitously borne by men whose strength was already sufficiently taxed by their own professional duties. Otherwise the lectures would have certainly been continued, for we were all fully persuaded that no mode of commencing science teaching for the people is so effective as this, or so likely to ripen into a permanent demand for scientific education amongst the working classes. As a proof of this, I may add that for two winters a class was formed in connection with these lectures for regular instruction in Chemistry under an able Government science master-one of my pupils, who had gradually raised himself from the position of a common factory hand. For this instruction sixty working men each paid $2 s$. $6 d$. for thirteen lessons. I often looked in upon them, and a more hard-working and enthusiastic class I never had the good fortune to see.

If such science lectures, followed up by regular science intstrution, could be permanently established every winter, under careful and thoronghly competent teachers, in each of our great centres of industry, what invaluable results might not be accomplished! This is truly a subject worthy of the attention of some of our wealthy philanthropists; if indeed, Government does not take the matter up. How much better would it be to devote money to the establishment of such a series of science classes, than, as is too often the custom, to employ it for building an almshouse!

Owens College, Manchester, Nov. 23, 1869.

\section{Changes in Jupiter}

DURING the months of October and November the planet Jupiter has presented a spectacle of singular and almost unexampled beauty. The belts on the planet are more than usually numerous, and they display a greater variety of colours than $I$ have ever yet seen ascribed to them. The equatorial belt, which has been for years the brightest part of the planet, is now not nearly so bright as the light belts to. the north and south; usually it has been free from markings, now it is often covered with markings, which resemble piled-up cumulus clouds : it has generally been colourless, shining with a silver-grey, or pearly lustre-now it is of a rich deep yellow, greatly resembling the colour of electrotyped gold.

The woodcut represents Jupiter as it was seen on the night of the 9th of March in a reflecting telescope with a silvered glass mirror of $12 \frac{1}{4}$ inches diameter. The upper part of the planet is the $S$. pole. On this portion of the disc there are three dark belts, while on the $N$. there are only two.

The poles of the planet are ashy blue, and the darker belts nearest to them present a darker tint of the same colour. The bright belts next these are pearly-white, and shine more brilliantly than any other portion of the planet. The dark belts next to the central bright belts are coppery red. As already mentioned, the 